\section{Unresolved issues in hepatitis C: The role of liver non-parenchymal cells and semaphorins}

\author{
Adriana Vince, ${ }^{1-3}$ Neven Papic ${ }^{1,3}$ \\ ${ }^{1}$ Department for Viral Hepatitis, \\ University Hospital for Infectious \\ Diseases Zagreb, Croatia; ${ }^{2}$ School of \\ Medicine, University of Zagreb, Croatia; \\ ${ }^{3}$ ESCMID Study Group for Viral \\ Hepatitis, Basel, Switzerland
}

\section{Editorial}

With broad usage of direct acting antivirals (DAAs) the global epidemics of hepatitis $\mathrm{C}$ will probably come to an end in next 20 years. ${ }^{1,2}$ The price of DAAs is still high in European countries and in USA, but it is plausible to assume that the availability of generic drugs will make the treatment possible for the majority of diagnosed patients. So we will be able to eliminate the virus without really understanding the pathophysiology of chronic infection, fibrogenesis and carcinogenesis. Substantial number of treated patients will therefore have to be followed up for cirrhosis and hepatocellular carcinoma.

There is growing evidence that liver non-parenchymal cells, specifically liver sinusoidal endothelial cells (LSEC) and Kupffer cells (KC), may play key roles in regulating immune responses and facilitating tolerance induction. ${ }^{3,4}$ Previously published gene expression analyses have revealed new disease specific changes in gene expression, identified potential biomarkers of $\mathrm{HCV}$ infection and suggested a new mechanism of host cell-virus interaction that results in viral particle assembly, secretion and infectivity. ${ }^{5-9}$ In vitro $\mathrm{HCV}$ JFH-1 infection studies have shown different gene expression repertoires; unlike macrophages that demonstrated a broad increase in IL1 $\beta$ and NFKB-responsive proinflammatory cytokines and chemokines, transcriptome changes in hepatocytes enable the replicative infection, while LSEC favor the transcription of immunomodulators that can silence the inflammatory reaction and favor fibrogenesis. ${ }^{5,7-10}$ Multiple strategies by which HCV evades the surveillance of the host immune system are proposed and yet to be explained.

These in vitro cell cultures studies suggested the connection of immune sema- phorins with HCV infection. Semaphorins are a class of secreted and membrane-bound proteins that regulate key cellular functions involved in cell-cell communication. The importance of semaphorins and plexins has been emphasized by their discovery in many organ systems including the nervous, epithelial, and immune systems as well as diverse cell processes including angiogenesis, embryogenesis and cancer. ${ }^{11,12}$ Studies of plexins and semaphorins have revealed that several members of these families are involved in a series of immune cell interactions, which ultimately influence the outcome of the immune response and substantially influence the level of inflammation. ${ }^{11,12}$ Interestingly, semaphorins play the opposite roles in innate versus adaptive immune response, amplifying inflammation while dampening $\mathrm{T}$-cell proliferation and activation. ${ }^{11,13,14}$ Although immune semaphorins are crucial to various phases of the immune response, so far semaphorins have not been linked with HCV infection.

Previously mentioned gene expression studies have linked several semaphorins with HCV infection: SEMA3C was shown to increase the production/secretion of several extracellular matrix components (fibronectin, elastin, collagen) and promoting factors (CTGF, IL6 and TGF- $\beta 1$ ), and the expression of SEMA3C correlated positively with the degree of fibrosis in adipose tissue; ${ }^{15}$ SEMA6B and SEMA6D might bind to and activate dendritic cells and increase type I interferon production. ${ }^{16}$

We have been able to show in our Croatian Science Foundation project Infectomics study of the human liver nonparenchymal cells in chronic hepatitis $C$ that serum concentrations of secreted semaphorins are higher in HCV infected patients, and their serum concentration correlate with the degree of liver fibrosis. ${ }^{17}$ Immunohistochemistry in transplanted livers revealed the absence of semaphorins in healthy livers in comparison with strong positivity in LSEC and $\mathrm{KC}$ in explanted cirrhotic $\mathrm{HCV}$ positive livers (Vince A., unpublished data). Furthermore, results of that research imply the usage of semaphorins as predictive markers of liver cirrhosis, stronger then APRI score and FIB4 test. ${ }^{17}$ These results provide first evidence that semaphorins are involved in immune response to chronic $\mathrm{HCV}$ infection. This might have import clinical implications as well, since their concentration correlates with the extent of liver disease, they might be considered as new biomarkers of liver fibrogenesis.

Although the serum concentration of semaphorins in people who develop hepatocellular carcinoma should be evaluated fur-
Correspondence: Adriana Vince, University Hospital for Infectious Diseases Zagreb, Mirogojska 8, 10000 Zagreb, Croatia.

Tel.: +385.91.4012603.

E-mail: avince@bfm.hr

Key words: chronic hepatitis C, liver cirrhosis, liver sinusoidal endothelial cells, semaphorins.

Contributions: the authors contributed equally.

Conflict of interest: the authors declare no potential conflict of interest.

Conference presentations: Data were presented in part at ECCMID 2017, Vienna, Austria.

Funding: This project was supported by Croatian Science Foundation (project 4241, Infectomics Study of Human Liver Nonparenchymal Cells in Chronic hepatitis C) and by the grant "Strengthening the capacity of CerVirVac for research in virus immunology and vaccinology", KK.01.1.1.01.0006, awarded to the Scientific Centre of Excellence for Virus Immunology and Vaccines and cofinanced by the European Regional Development Fund.

Received for publication: 22 February 2018. Accepted for publication: 22 February 2018.

This work is licensed under a Creative Commons Attribution-NonCommercial 4.0 International License (CC BY-NC 4.0).

CC Copyright A. Vince and N. Papic, 2018 Licensee PAGEPress, Italy

Infectious Disease Reports 2018; 10:7651

doi:10.4081/idr.2018.7651

ther, recent studies showed that semaphorins that restrict cell migration and angiogenesis are often downregulated, while those that support cancer progression and metastatic spreading are frequently upregulated in other cancers. ${ }^{18}$ It was also shown that blocking these molecules effectively reduce tumor angiogenesis and metastatic spreading in preclinical trials in mice. ${ }^{18-20}$

These data validate the identification of semaphorin signals as a potential biomarker of infection and fibrosis stage in chronic viral hepatitis and promising therapeutic targets in liver cancer.

\section{References}

1. Spengler U. Direct antiviral agents (DAAs) - A new age in the treatment of hepatitis $\mathrm{C}$ virus infection. Pharmacol 
Ther 2017.

2. WHO. Combating hepatitis B and C to reach elimination by 20302016 [cited 2016. Available from: http://www.who.int/hepatitis/publications/hep-elimination-by-2030-brief/en/

3. Connolly MK, Bedrosian AS, Malhotra A, et al. In hepatic fibrosis, liver sinusoidal endothelial cells acquire enhanced immunogenicity. J Immunol 2010;185:2200-8.

4. Knolle PA, Limmer A. Neighborhood politics: the immunoregulatory function of organ-resident liver endothelial cells. Trends Immunol 2001;22:432-7.

5. Folkers ME, Delker DA, Maxwell CI, et al. ENCODE tiling array analysis identifies differentially expressed annotated and novel 5' capped RNAs in hepatitis $\mathrm{C}$ infected liver. PloS One 2011;6:e14697.

6. Kurelac I, Lepej SZ, Grlgic I, et al. Chemokine CXCL10 at week 4 of treatment predicts sustained virological response in patients with chronic hepatitis C. J Interferon Cytokine Res 2012;32:386-91.

7. Negash AA, Ramos HJ, Crochet N, et al. IL-1beta production through the NLRP3 inflammasome by hepatic macrophages links hepatitis $\mathrm{C}$ virus infection with liver inflammation and disease. PLoS Pathogens 2013;9: e1003330.

8. Papic N, Delker D, Liu S, et al. RNA Sequencing analysis of human liver sinusoidal endothelial cells reveals evidence for an anti-inflammatory role during HCV infection. J Hepatol 2013; 58:S146-S7.

9. Papic N, Maxwell CI, Delker DA, et al. RNA-sequencing analysis of 5' capped RNAs identifies many new differentially expressed genes in acute hepatitis C virus infection. Viruses 2012;4:581612.

10. Papic N, Delker D, Rong X, et al. Kupffer Cells are a major source of IL1 and other drivers of inflammation in chronic hepatitis C. Hepatology 2012;56:704A-A.

11. Roney K, Holl E, Ting J. Immune plexins and semaphorins: old proteins, new immune functions. Protein Cell 2013;4:17-26.

12. Kumanogoh A, Kikutani $H$. Immunological functions of the neuropilins and plexins as receptors for semaphorins. Nature reviews Immunology 2013;13:802-14.

13. Wen H, Lei Y, Eun SY, Ting JP. PlexinA4-semaphorin 3A signaling is required for Toll-like receptor- and sepsisinduced cytokine storm. J Exp Med 2010;207:2943-57.

14. Yamamoto M, Suzuki K, Okuno T, et al.
Plexin-A4 negatively regulates $\mathrm{T}$ lymphocyte responses. Int Immunol 2008;20:413-20.

15. Mejhert N, Wilfling F, Esteve D, et al. Semaphorin $3 \mathrm{C}$ is a novel adipokine linked to extracellular matrix composition. Diabetologia 2013;56:1792-801.

16. Watarai H, Sekine E, Inoue S, et al. PDC-TREM, a plasmacytoid dendritic cell-specific receptor, is responsible for augmented production of type I interferon. Proc Natl Acad Sci USA 2008;105:2993-8.

17. Grgić I ZLS, Gorenec L, Papic N, et al. Increased expression of semaphorin $3 \mathrm{c}$ and $6 \mathrm{~b}$ in chronic hepatitis $\mathrm{C}$ is associated with the severity of liver disease. ECCMID 2017; Vienna, Austria 2017.

18. Capparuccia L, Tamagnone L. Semaphorin signaling in cancer cells and in cells of the tumor microenvironment - two sides of a coin. J Cell Sci 2009;122:1723-36.

19. Casazza A, Fu X, Johansson I, et al. Systemic and targeted delivery of semaphorin $3 \mathrm{~A}$ inhibits tumor angiogenesis and progression in mouse tumor models. Arterioscler Thromb Vasc Biol 2011;31:741-9.

20. Worzfeld T, Swiercz JM, Looso M, et al.. ErbB-2 signals through Plexin-B1 to promote breast cancer metastasis. J Clin Invest 2012;122:1296-305. 